\title{
IMPLEMENTASI TOTAL PRODUCTIVE MAINTENANCE PADA MESIN PRESS DRYER DI PT. TRI TUNGGAL LAKSANA
}

\author{
Sigit Dwi Cahyono' ${ }^{1}$, Nelly Budiharti ${ }^{2}$ \\ ${ }^{1)}$ Pegawai Negeri Sipil Dinas Tenaga Kerja Dan Transmigrasi Provinsi Jawa Timur \\ ${ }^{2)}$ Dosen Pasca Sarjana Jurusan Teknik Industri ITN Malang \\ sigitc49@gmail.com
}

\begin{abstract}
Abstrak, PT Tri Tunggal Laksana merupakan perusahaan yang bergerak pada industri pengolahan kayu. Dalam proses produksinya perusahaan menggunakan mesin Press Dryer untuk menurunkan kadar air pada lembaran kayu (veneer). Selama periode produksi July-Desember 2019, mesin mengalami breakdown selama 185,5 jam dari total jam kerja selama 6 bulan yaitu 2.100 jam atau sebesar 8,83\%. Perusahaan perlu mengidentifikasi faktor -faktor yang mempengaruhi efektivitas mesin serta melakukan analisis terhadap aktivitas maintenance yang dapat digunakan sebagai bahan masukan dalam penerapan Total Productive Maintenance (TPM). Penelitian ini bertujuan mengukur tingkat efektivitas mesin press dryer, menentukan faktor yang mempengaruhi nilai Overall Equipment Effectiveness (OEE), dan mengidentifikasi kerugian/losses yang terjadi, serta memberikan usulan perbaikan penerapan TPM. Berdasarkan hasil penelitian, diperoleh nilai OEE pada mesin press dryer sebesar $72,3 \%$ yang masuk pada kategori tingkat yang wajar (fairly typical level) dimana masih banyak ruang perbaikan yang harus dilakukan perusahaan. Six Big Losses yang paling tinggi sebagai faktor yang mempengaruhi OEE mesin press dryer yaitu reduce speed dan breakdown losses. Usulan perbaikan yang dapat dilakukan yaitu dengan memperbaiki SOP bagi operator sehingga operator memiliki peran dan tanggung jawab terhadap mesin yang dioperasikan.
\end{abstract}

Kata Kunci: Total Productive Maintenance, Overall Equipment Effectiveness, Six Big Losses

\section{PENDAHULUAN}

Tantangan dunia industri saat ini mengharuskan perusahaan melakukan segala tindakan dan kebijakan yang dapat mendukung efektifitas dan efisiensi proses produksi untuk mencapai tujuan perusahaan yaitu mendapatkan keuntungan atau laba perusahaan. Perusahaan harus berjuang untuk dapat mencapai suatu tahapan produksi yang efisien, efektif dan produktif sehingga tujuan perusahaan dapat tercapai (Rusli Ananta, 2017).

Dalam upaya untuk mencapai tujuan, perusahaan seringkali menghadapi berbagai permasalahan baik dalam hal bahan baku, mesin produksi, sumber daya manusia, maupun faktor eksternal misalnya kondisi cuaca maupun bencana alam. Terjadinya kerusakan mesin atau berhentinya proses produksi akibat mesin rusak mengharuskan perusahaan untuk memutuskan bagaimana perusahaan manufaktur tetap bisa melakukan proses produksi tanpa adanya pemborosan waktu yang ditimbulkan. Faktanya, tindakan perbaikan yang dilakukan belum mampu menjawab pada akar persoalan yang terjadi, sehingga hal tersebut akan menimbulkan kerugian akibat biaya yang harus dikeluarkan oleh kerusakan yang terjadi dan berkurangnya hasil produksi. Pada dasarnya, perawatan dilakukan agar mesin selalu dalam kondisi bagus dan baik, sehingga tetap siap pakai serta membantu ketahanan yang lebih lama (Wildan Wiranata, 2017).

Penerapan TPM pada perusahaan terbukti memberikan perubahan yang baik pada perusahaan berupa peningkatan produktivitas, peningkatan kualitas, pengendalian biaya, ketepatan pengiriman produk kepada konsumen, menjaga keselamatan pekerja dan peningkatan semangat dalam menciptakan tempat kerja yang kondusif untuk operasional perusahaan (Sigit Priyono, 2019). TPM dapat menjadi program fundamental pengembangan pemeliharaan mesin yang melibatkan seluruh pekerja.

Penelitian ini fokus pada implementasi Total Productive Maintenance di PT. Tri Tunggal Laksana demi meningkatkan produktivitas proses produksinya yaitu pada mesin press dryer. Metode Overall Equipment Effectiveness (OEE) diharapkan dapat memberikan gambaran mengenai kerugiankerugian (six big losses). Berdasarkan permasalahan di atas, penelitian ini bertujuan untuk mengukur tingkat efektivitas mesin press dryer, menentukan faktor penyebab nilai Overall Equipment Effectiveness (OEE) rendah dan mengidentifikasi kerugian/losses yang 
terjadi, serta memberikan usulan perbaikan penerapan TPM perusahaan.

Menurut (Nakajima, 1988) total productive maintenance (TPM) menekankan bahwa pendayagunaan dan keterlibatan sumber daya manusia dan sistem preventive maintenance berguna untuk memaksimalkan efektifitas peralatan dengan melibatkan semua departemen dan fungsional organisasi. Menurut Vakatesh (2007) dalam Eko Nursubiyantoro (2016) TPM sesuai dengan namanya terdiri dari atas tiga buah suku kata, yaitu:

\section{Total}

TPM mempertimbangkan berbagai aspek dan melibatkan seluruh personil yang ada, mulai dari tingkatan jabatan tertinggi hingga ke jajaran tingkat bawah.

\section{Productive}

Menitik beratkan pada segala usaha untuk selalu melakukan pemeliharaan dengan kondisi produksi tetap berjalan dan meminimalkan masalah-masalah yang terjadi di produksi saat pemeliharaan berlangsung.

\section{Maintenance}

Melaksanakan pemeliharaan dengan tetap menjaga peralatan secara mandiri yang dilakukan oleh operator produksi, agar kondisi peralatan tetap bagus dan terpelihara dengan jalan membersihkannya, melakukan pelumasan dan memperhatikan kondisi mesin secara optimal.

Tujuan Total Productive Maintenance adalah memastikan semua peralatan atau mesin berada dalam kondisi kerja yang baik untuk menghindari kerusakan dan terjadinya delay dalam proses manufaktur. Overall Equipment Effectiveness (OEE) adalah sebuah metrik yang fokus pada seberapa efektifnya suatu operasi produksi dijalankan. Hasil penilaian dapat dinyatakan dalam bentuk yang bersifat umum sehingga memungkinkan perbandingan antara unit manufaktur di industri yang berbeda. Selain mengetahui performa peralatan. Pihak pengambil keputusan dapat mengetahui dengan jelas kapasitas peralatan yang ada serta bisa mengambil kebijakan yang tepat.

Perawatan (maintenance) adalah metode yang digunakan untuk menjaga dan memelihara mesin dari gangguan dan kerusakan saat kondisi yang tidak menentu. Fungsi perawatan adalah memperbaiki mesin atau peralatan (equipment) yang rusak dan menjaga agar selalu dalam kondisi siap dioperasikan (Mukril, 2014:2). Sistem Perawatan merupakan salah satu kegiatan utama dalam suatu perusahaan. Dalam praktiknya, ada beberapa faktor penyebab kerusakan mesin, yaitu : keausan (wear out), korosi (corrocion) dan kelelahan (fatigue) (Rommy Febri Prabowo, 2020). Tujuan utama dari sistem perawatan adalah untuk menjaga dan menghindarkan mesin atau peralatan dari kerusakan yang berat, supaya tidak diperlukan biaya yang terlalu mahal untuk melakukan perawatan dan waktu yang cukup lama. Prinsip utama dari sistem perawatan terdiri atas dua hal yaitu menekan atau memperpendek periode kerusakan sampai batas minimum dan menghindari kerusakan yang tidak terencana. Jenis-jenis perawatan yaitu:

1.Planned Maintenance (Pemeliharaan Terencana)

2.Unplanned Maintenance (Pemeliharaan Tidak Terencana)

3.Autonomous Maintenance (Pemeliharaan Mandiri)

\section{METODE}

Metode Pengumpulan Data

Penelitian ini dilakukan di PT. Tri Tunggal Laksana Unit Blitar khususnya pada unit produksi veneer. Objek penelitian adalah mesin press dryer yang digunakan untuk mengurangi kadar air dalam lembaran veneer. Pengumpulan data dilakukan melalui studi Pustaka dan studi lapangan guna mendapatkan data yang sesuai kondisi di perusahaan. Observasi adalah pengamatan yang dilakukan dengan sengaja dan sistematis terhadap aktivitas individu atau obyek lain yang diselidiki. Observasi dilakukan pada unit produksi press dryer sedangkan data primer diperoleh dari departemen produksi dan departemen engineering sebagai penanggung jawab maintenance peralatan produksi. Datadata yang diambil merupakan data primer yaitu data produksi serta data dari divisi maintenance mengenai downtime mesin serta perbaikan yang dilakukan terhadap mesin press dryer. Sesuai dengan periode penelitian, data yang diambil yaitu data selama 6 bulan dari bulan JuliDesember tahun 2019. 
Teknik Analisis Data

Penelitian ini menggunakan analisis Overall Equipment Efectiveness (OEE) untuk mencari nilai efektifitas mesin press dryer di PT Tri Tunggal Laksana Unit Blitar. Langkahlangkah yang dilakukan adalah sebagai berikut: 1. Perhitungan Availability Ratio

Availability Ratio digunakan untuk mengukur keseluruhan waktu ketika sistem tidak beroperasi karena terjadi kerusakan alat, persiapan produksi dan penyetelan ulang. Dengan kata lain Availability diukur dari total waktu dimana peralatan dioperasikan setelah dikurangi waktu kerusakan alat dan waktu persiapan serta penyesuaian mesin yang juga mengindikasikan rasio aktual antara Operating Time terhadap waktu operasi yang tersedia (Agustiady, 2016). Waktu pembebanan mesin dipisahkan dari waktu produksi secara teoritis serta waktu kerusakan dan waktu perbaikan yang direncanakan. Hal ini memotivasi agar mengurangi Planned Downtime melalui peningkatan efisiensi penyesuaian alat serta waktu untuk aktifitas perawatan yang sudah direncanakan.

Availability Ratio $=\frac{\text { Loading Time }- \text { Downtime }}{\text { Loading Time }} \times 100 \%$

\section{Perhitungan Performance Ratio}

Performance Ratio mengukur rasio kecepatan operasi aktual dari peralatan dengan kecepatan ideal berdasarkan kapasitas desain awal.

Performance Ratio $=\frac{\text { Output } x \text { Ideal Cycle Time }}{\text { Operating Time }} \times 100 \%$

\section{Perhitungan Quality Ratio}

Quality Ratio fokus pada kerugian kualitas berupa berapa banyak produk yang rusak yang diakibatkan adanya kerusakan peralatan, yang selanjutnya dikonversi menjadi waktu dengan pengertian lain seberapa banyak waktu peralatan yang dihabiskan untuk menghasilkan produk yang rusak tersebut.

Quality Ratio $=\frac{\text { output }- \text { RejucedYield }- \text { Reject }}{\text { Output }} \times 100 \%$

4. Perhitungan Overall Equipment Effectiveness

OEE memberi gambaran mengenai kinerja mesin atau peralatan dan memberikan nilai yang akurat untuk mengetahui tingkat efektifitas mesin tersebut. Setelah ketiga perhitungan faktor diatas telah dapat diketahui, maka langkah selanjutnya adalah dengan mencari nilai dari overall equipment effectiveness (OEE) dengan rumus:

$\mathrm{OEE}=$ Availability $\times$ Performance $\times$ Quality

\section{Perhitungan Nilai Losses}

Perhitungan ini berguna untuk mengidentifikasi kerugian seperti kerugian karena alat, kerugian persiapan dan penyesuaian, kerugian kerusakan produk, serta kerugian tersembunyi seperti pengurangan kecepatan dan kerugian idle and minor stoppage. Breakdown Losses terjadi karena peralatan mengalami kerusakan atau perbaikan selama masa produksi.

\section{HASIL DAN PEMBAHASAN}

Perhitungan nilai OEE dan nilai losses yang diperoleh akan diidentifikasi berdasarkan jenis kerugian yang paling mempengaruhi rendahnya ketiga elemen OEE.

\section{Perhitungan Availability Ratio}

Availability ratio merupakan ratio yang menunjukkan penggunaan waktu yang tersedia untuk kegiatan operasi mesin atau peralatan. Waktu yang diukur ini ketika sistem tidak beroperasi karena kerusakan alat, persiapan produksi dan penyetelan peralatan. Availability merupakan ratio yang menggambarkan pemanfaatan waktu yang tersedia untuk kegiatan proses produksi. Untuk mendapatkan nilai availability, maka memerlukan data loading time, downtime dan operating time (Nina Hairiyah, 2019). Adapun perhitungan nilainya sebagai berikut:

1. Perhitungan Availability Ratio mesin Press Dryer bulan Juli 2019

$$
\begin{aligned}
\text { Availability Ratio }= & \frac{\text { Loading Time }- \text { Downtime }}{\text { Loading Time }} \times 100 \% \\
& =\frac{364,5 \mathrm{jam}-50,3 \mathrm{jam}}{364,5} \times 100 \% \\
& =86,20 \%
\end{aligned}
$$


Tabel 1 Rekapitulasi Data Availability Ratio Mesin Press Dryer Tahun 2019

\begin{tabular}{|c|l|c|c|c|}
\hline $\begin{array}{c}\text { No } \\
\cdot\end{array}$ & Bulan & $\begin{array}{c}\text { Loading } \\
\text { Time } \\
\text { (jam) }\end{array}$ & $\begin{array}{c}\text { Downtim } \\
e \\
\text { (jam) }\end{array}$ & $\begin{array}{c}\text { Availability } \\
\text { Ratio } \\
(\%)\end{array}$ \\
\hline 1 & Juli & 364,5 & 50,3 & 86,20 \\
\hline 2 & Agustus & 351 & 37,3 & 89,37 \\
\hline 3 & September & 337,5 & 79,4 & 76,47 \\
\hline 4 & Oktober & 310,5 & 72,6 & 76,62 \\
\hline 5 & November & 337,5 & 31,4 & 90,70 \\
\hline 6 & Desember & 324 & 52 & 83,95 \\
\hline \multicolumn{5}{|c|}{ Rata-rata } \\
\hline
\end{tabular}

Sumber: Pengolahan Data (2020)

Data availability ratio atau rasio ketersediaan mesin press dryer bulan Juli hingga bulan Desember 2019 terlihat pada tabel 1. Nilai availability ratio tertinggi pada bulan November sebesar $90,70 \%$.

\section{Perhitungan Performance Ratio}

Performance ratio dihitung dengan cara mengalikan waktu siklus ideal dengan output dari mesin press dryer. Adapun perhitungannya yaitu sebagai berikut:

Perhitungan Performance Ratio mesin press dryer bulan Juli 2019

$$
\begin{aligned}
\text { Performance Ratio }= & \frac{\text { output } x \text { Ideal Cycle Time }}{\text { Operating Time }} \times 100 \% \\
& =\frac{632,04 \mathrm{~m} 3 \times 0,47 \mathrm{jam}}{292,20 \mathrm{jam} / \mathrm{m} 3} \times 100 \% \\
& =100,29 \%
\end{aligned}
$$

Tabel 2 Rekapitulasi Data Performance Ratio Mesin Press Dryer Tahun 2019

\begin{tabular}{|c|l|c|c|c|c|}
\hline $\begin{array}{c}\mathrm{N} \\
\mathrm{o}\end{array}$ & Bulan & $\begin{array}{c}\text { Output } \\
\left(\mathrm{m}^{3}\right)\end{array}$ & $\begin{array}{c}\text { Ideal } \\
\text { Cycle } \\
\text { Time } \\
(\mathrm{jam})\end{array}$ & $\begin{array}{c}\text { Operatin } \\
\text { g Time } \\
\left(\mathrm{jam} / \mathrm{m}^{3}\right)\end{array}$ & $\begin{array}{c}\text { Performan } \\
\text { ce Ratio } \\
(\%)\end{array}$ \\
\hline 1 & Juli & 632,04 & 0,47 & 296,20 & 100,29 \\
\hline 2 & Agustus & 608,06 & 0,39 & 296,37 & 80,02 \\
\hline 3 & September & 764,18 & 0,24 & 241,43 & 75,97 \\
\hline 4 & Oktober & 932,04 & 0,19 & 222,57 & 79,56 \\
\hline 5 & November & 1291,6 & 0,20 & 289,43 & 89,25 \\
\hline 6 & Desember & $\begin{array}{c}1505,9 \\
9\end{array}$ & 0,17 & 256,00 & 100,01 \\
\hline \multicolumn{5}{|c|}{ Rata-rata } \\
\hline
\end{tabular}

Sumber: Pengolahan Data (2020)

Data pada tabel 2 merupakan rekapitulasi data performance ratio mesin press dryer pada bulan Juli hingga Desember tahun 2019. Nilai performance ratio bulan Juli dan Desember mencapai $100 \%$. Nilai rasio tersebut melebihi standar global yaitu sebesar 95\%.

\section{Perhitungan Quality Ratio}

Quality Ratio adalah ratio yang menunjukkan kemampuan peralatan dalam menghasilkan produk yang sesuai standar. Ratio ini difokuskan pada kerugian kualitas berupa berapa banyak produk yang rusak yang terjadi berhubungan dengan peralatan, yang selanjutnya dikonversi menjadi waktu. Artinya, seberapa banyak waktu peralatan yang dikonsumsi untuk menghasilkan produk yang rusak dalam periode produksi. Adapun perhitungan sebagai berikut:

Perhitungan Quality Ratio mesin press dryer bulan Juli 2019

Quality Ratio $=\frac{\text { output }- \text { Rejuced Yield }- \text { Reject }}{\text { Output }} \times 100 \%$

$$
\begin{aligned}
& =\frac{632,04-0-8,44}{632,04} \times 100 \% \\
& =98,66 \%
\end{aligned}
$$

Tabel 3 Rekapitulasi Data Quality Ratio Mesin Press Dryer Tahun 2019

\begin{tabular}{|c|l|c|c|c|c|}
\hline No. & Bulan & $\begin{array}{c}\text { Output } \\
\left(\mathrm{m}^{3}\right)\end{array}$ & $\begin{array}{c}\text { Reduced } \\
\text { Yield } \\
\left(\mathrm{m}^{3}\right)\end{array}$ & $\begin{array}{c}\text { Reject } \\
\left(\mathrm{m}^{3}\right)\end{array}$ & $\begin{array}{c}\text { Quality } \\
\text { Ratio } \\
(\%)\end{array}$ \\
\hline 1 & Juli & 632,04 & 0 & 8,44 & 98,66 \\
\hline 2 & Agustus & 608,06 & 0 & 10,12 & 98,34 \\
\hline 3 & September & 764,18 & 0 & 15,2 & 98,01 \\
\hline 4 & Oktober & 932,04 & 0 & 17,68 & 98,10 \\
\hline 5 & November & 1291,6 & 0 & 8,4 & 99,35 \\
\hline 6 & Desember & 1505,99 & 0 & 24,5 & 98,37 \\
\hline \multicolumn{5}{|c|}{ Rata-rata } & 98,47 \\
\hline
\end{tabular}

Sumber: Pengolahan Data (2020)

Nilai quality ratio mesin press dryer pada tabel 3 menunjukkan bahwa rasio kualitas sangat baik pada keseluruhan bulan. Nilai rata-rata mendekati rasio standar global yaitu 99,90\%.

4. Perhitungan Nilai OEE Mesin Press Dryer

Setelah perhitungan masing-masing rasio diperoleh, maka selanjutnya menghitung nilai OEE pada mesin debarker. Adapun perhitungannya sebagai berikut:

Perhitungan nilai OEE mesin press dryer bulan Juli 2019 
$\mathrm{OEE}=$ Availability Ratio $\times$ Performance Ratio $\mathrm{x}$ Quality Ratio $=86,20 \% \times 100,29 \% \times 98,66 \%$

$=85,29 \%$

Tabel 4 Rekapitulasi Data OEE Mesin Press Dryer Tahun 2019

\begin{tabular}{|c|l|c|c|c|c|}
\hline No & Bulan & $\begin{array}{c}\text { Availability } \\
\text { Ratio } \\
(\%)\end{array}$ & $\begin{array}{c}\text { Performan } \\
\text { Ratio } \\
(\%)\end{array}$ & $\begin{array}{c}\text { Quality } \\
\text { Ratio } \\
(\%)\end{array}$ & $\begin{array}{c}\text { OEE } \\
(\%)\end{array}$ \\
\hline 1 & Juli & 86,20 & 100,29 & 98,66 & 85,3 \\
\hline 2 & Agustus & 89,37 & 80,02 & 98,34 & 70,3 \\
\hline 3 & September & 76,47 & 75,97 & 98,01 & 57 \\
\hline 4 & Oktober & 76,62 & 79,56 & 98,10 & 59,8 \\
\hline 5 & November & 90,70 & 89,25 & 99,35 & 80,4 \\
\hline 6 & Desember & 83,95 & 100,01 & 98,37 & 82,6 \\
\hline \multicolumn{2}{|c|}{ Rata-rata } & 83,89 & 87,52 & 98,47 & 72,3 \\
\hline
\end{tabular}

Sumber: Pengolahan Data (2020)

Tabel 4 memperlihatkan nilai OEE pada mesin press dryer pada bulan Juli hingga bulan Desember 2019. Nilai OEE tertinggi pada bulan Juli sebesar 85,29\%. Rata-rata OEE selama enam bulan yaitu sebesar $72,30 \%$.

\section{Perhitungan Nilai Six Big Losses}

Analisis perhitungan six big losses bertujuan mengetahui faktor losses yang memberikan kontribusi terbesar dalam rendahnya nilai efektivitas mesin Press Dryer.

Tabel 5 Nilai Six Big Losses Mesin Press Dryer

\begin{tabular}{|c|l|c|}
\hline No. & \multicolumn{1}{|c|}{ Losses } & Nilai (\%) \\
\hline 1 & Breakdown Losses & 55,95 \\
\hline 2 & $\begin{array}{l}\text { Setup and Adjustment } \\
\text { Losses }\end{array}$ & 40,74 \\
\hline 3 & Idling and Minor Stoppages & 13,62 \\
\hline 4 & Reduce Speed Losses & 70,87 \\
\hline 5 & Reduce Yield / Scrap Losses & 0,00 \\
\hline 6 & $\begin{array}{l}\text { Defect in Process and } \\
\text { Rework }\end{array}$ & 25,45 \\
\hline
\end{tabular}

Sumber: Pengolahan Data (2020)

Tabel 5 menunjukkan rekapitulasi waktu-waktu dari keenam kerugian besar pada mesin press dryer. Setelah diketahui waktu kemudian di persentasekan dan diurutkan dari waktu paling tinggi ke rendah, kemudian dijadikan diagram pareto. Nilai dengan angka nol (0) tidak dimasukkan. Diagram pareto ditunjukkan pada gambar 1

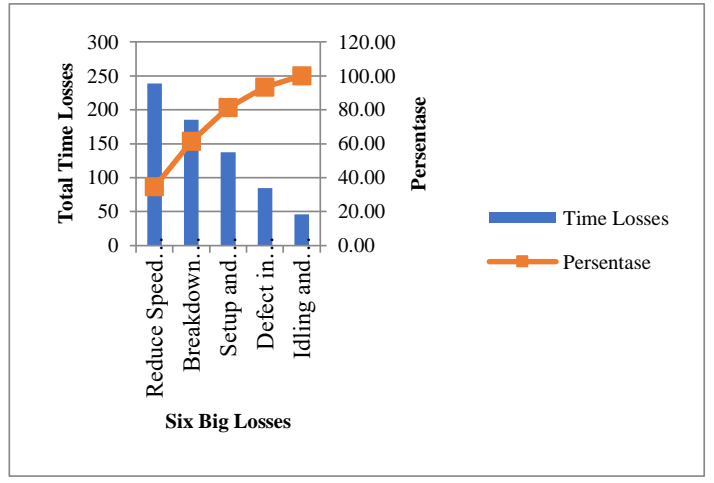

Sumber: Pengolahan Data (2020)

Gambar 1 Diagram Pareto Six Big Losses Mesin Press Dryer

Gambar 1 Menunjukkan bahwa faktor six big losses yang paling memberikan pengaruh terhadap kehilangan waktu mesin press dryer adalah reduce speed losses yaitu 70,87\% dan breakdown losses $(55,95 \%)$ selama 6 bulan waktu produksi. Reduce Speed merupakan kerugian yang terjadi akibat peralatan dioperasikan dibawah standar kecepatan. Breakdown losses merupakan kerugian yang disebabkan adanya kerusakan mesin yang memerlukan suatu perbaikan. Contoh dari breakdown losses yaitu waktu rehat pekerja selama masa perbaikan mesin.

\section{Usulan Perbaikan}

Dari hasil analisa terhadap mesin Press Dryer di PT Tri Tunggal Laksana, ada beberapa hal yang dapat dilakukan perusahaan untuk meningkatkan efektifitas dan efisiensi mesin press dryer yaitu dengan memberikan SOP (standar operasional prosedur) pada karyawan serta operator mesin press dryer yaitu sebagai berikut:

1. Kepala shift memberikan rencana kerja kepada tenaga kerja bagian mesin press dryer setiap pagi atau pergantian shift.

2. Tenaga kerja bagian mesin press dryer wajib menggunakan APD yang sudah disediakan dan tidak melanjutkan pekerjaan apabila APD tidak ada dan apabila tenaga kerja tidak menggunakan APD, kepala divisi atau kepala shift wajib melarang untuk melaksanakan pekerjaan. 
3. Tenaga kerja bagian mesin press dryer memeriksa seluruh alat pelindung mesin dan komponen emergency bahwa sudah bekerja sesuai fungsinya.

4. Tenaga kerja bagian mesin press dryer memeriksa kondisi bagian mesin utama yaitu kondisi temperatur $\left(38^{\circ} \mathrm{C}\right.$ s.d $40^{\circ} \mathrm{C}$ ), Platen harus bersih, tomboltombol panel mesin Press dryer berfungsi dan stik untuk mengambil dan meletakan veneer harus sesuai standarnya dan bersih.

5. Tenaga kerja bagian mesin press dryer mengisi atau mencatat chek list pemeriksaan.

6. Tenaga kerja bagian mesin press dryer segera melaporkan ke kepala divisi atau kepala shift apabila kondisi mesin tidak baik atau ada komponen yang rusak.

7. Tenaga kerja bagian mesin press dryer memastikan mesin press dryer berfungsi dengan baik dan berjalan dengan normal.

8. Mencatat dan melaporkan hasil kerjanya pada akhir shift, yaitu berupa hasil target kerjanya serta kondisi mesin press dryer.

\section{KESIMPULAN DAN SARAN \\ Kesimpulan}

Dari pembahasan dan analisis yang dilakukan dalam penelitian didapatkan nilai rata-rata OEE mesin Press Dryer tahun 2019 adalah $72,30 \%$ dengan nilai rata-rata availability $83,89 \%$, nilai rata-rata performance $87,52 \% \%$, dan nilai rata-rata quality $98,47 \%$. Nilai OEE masih di bawah standart dunia yaitu $85 \%$. Faktor utama yang mempengaruhi nilai OEE pada mesin press dryer adalah reduce speed sebesar 70,87\% dan breakdown losses sebesar $55,95 \%$.

Usulan perbaikan dapat dilakukan dengan memberikan SOP yang jelas dan tegas terhadap operator dan karyawan di unit produksi press dryer. Dengan adanya usaha ini dapat menjadi dasar peningkatan kinerja mesin sehingga mencapai kondisi zero breakdown karena operator mempunyai peran penting dalam mengetahui kondisi mesin

\section{Saran}

Saran yang dapat penulis berikan pada perusahaan setelah melakukan penelitian ini adalah perusahaan sebaiknya memberikan porsi pelatihan yang cukup kepada operator serta personil pemeliharaan mesin agar memiliki keahlian yang memadai sehingga dapat segera menyelesaikan permasalahan yang terjadi.

\section{DAFTAR PUSTAKA}

Agustiady T, Cudney E. 2016. Total ProductiveMaintenance - Strategies and Implementation Guide.London: CRC Press, Taylor \& Francis Group.

Ananta, Rusli. 2017. Analisis Penerapan Total Productive Maintenance (Tpm) Menggunakan Overall Equipment Effectiveness (OEE): Studi Pada PT Kalbe Farma Tbk. Skripsi: Universitas Gajah Mada

Hairiyah, Nina. Amalia, R.R., Dan Wijaya, R.A. 2019. Analisis Total Productive Maintenance (TPM) Pada Stasiun Kernel Crushing Plant (KCP) Di PT. X. Jurnal Teknologi Pertanian Andalas Vol. 23, No.1.

Mukhril. 2014. Penerapan Pada Industri: Total Productive Maintenance (TPM) \& Total Quality Management (TQM). Tangerang: Megakarya.

Nakajima, S. 1988. Introduction to Total Productive Maintenance. Productivity Press. Cambridge.

Nursubiyantoro, Eko., Puryani, dan Mohamad Isnaini Rozaq. 2016. Implementasi Total Productive Maintenance (TPM) Dalam Penerapan Overall Equipment Effectiveness (OEE). Jurnal OPSI (Optimasi Sistem Industri), Vol. 9 No.1.

Oktaria, Susanti., 2011. Perhitungan dan Analisa Nilai Overall Equipment Effectiveness (OEE) Pada Proses Awal Pengolahan Kelapa Sawit (Studi Kasus: $P T . X)$. Depok: Universitas Indonesia.

Prabowo, Romy Febri., Hendrik Hariyono., Erry Rimawan. 2020. Total Productive Maintenance (TPM) pada Perawatan Mesin Grinding Menggunakan Metode Overall Equipment Effectiveness (OEE). Journal Industrial Servicess Vol. 5 No. 2 Maret 2020

Priyono, Sigit., Machfud., Agus Maulana. 2019. Penerapan Total Productive Maintenance (TPM) Pada Pabrik Gula Rafinasi di 
Indonesia. Jurnal Aplikasi Manajemen dan

Bisnis, Vol. 5 No. 2, Mei 2019

Wiranata, Wildan. 2017. Penerapan Total

Productive Maintenance (TPM) Di CV.

Sispra Jaya Logam Untuk Meningkatkan

Efektivitas Mesin Produksi. Pekanbaru:

Universitas Islam Negeri Sultan Syarif

Kasim Riau 